\title{
Desenvolvimento de método miniaturizado de extração para determinação de anfetaminas e seus derivados em amostras de fluido oral usando microextração líquido-líquido dispersiva (DLLME).
}

\section{Júlia M. M. Kahl*, Kelly F. da Cunha, Prof. Dr. José Luiz da Costa.}

\section{Resumo}

O consumo mundial de estimulantes de forma abusiva tem apresentado um aumento considerável e constante desde 2013, segundo dados do relatório de 2019 da UNODC. ${ }^{1}$ Este grupo de drogas contempla substâncias como anfetamina, metanfetamina e o "ecstasy" (MDA, MDEA e MDMA), que foram aplicados a técnica de microextração líquido-líquido dispersiva (DLLME), otimizados e validados por cromatografia líquida acoplada a espectrometria de massas (LC$\mathrm{MS} / \mathrm{MS})$.

\section{Palavras-chave:}

toxicologia, DLLME, LC-MS/MS.

\section{Introdução}

A anfetamina foi sintetizada pela primeira vez na Alemanha, pelo químico Lazar Edeleanu em 1887. Atualmente esta e outras substâncias, de estruturas químicas derivadas, são amplamente utilizadas como droga de abuso, como por exemplo a 3,4metilenodioximetanfetamina (MDMA), a 3,4metilenodioxietilanfetamina (MDEA) e a 3,4metilenodioxianfetamina (MDA). Estas moléculas atuam no sistema nervoso central como agonistas dos receptores adrenérgicos $\alpha 1$ e $\alpha 2$ levando a um aumento na liberação de serotonina, dopamina e norepinefrina, esse aumento dos neurotransmissores é responsável pelos efeitos observados. Nas análises toxicológicas, o fluido oral possui como principal vantagem a facilidade de coleta, que não é invasiva e pode ser realizada sob observação sem que haja constrangimento do paciente esta característica é fundamental para viabilizar a coleta da amostra em situações de campo. O presente trabalho tem por objetivo desenvolver e validar um método analítico baseado em microextração líquido-líquido dispersiva (DLLME) e cromatografia líquida acoplada à espectrometria de massas sequencial (LC-MS/MS) para determinação de anfetamina, metanfetamina, MDMA, MDEA e MDA em amostras de fluido oral.

\section{Resultados e Discussão}

O procedimento de extração por DLLME foi otimizado durante a etapa de desenvolvimento. Os parâmetros otimizados foram: solvente extrator (clorofórmio e diclorometano) e dispersor (acetonitrila e metanol), além dos volumes destes, realizado a partir de planejamento de experimentos (fatorial $2^{4}$ ). Nesta etapa do trabalho foram utilizadas amostras de saliva branca fortificadas com soluções de trabalho dos analitos nas concentrações dos controles.

Para a extração, a uma alíquota de $50 \mu \mathrm{L}$ da amostra coletada com o dispositivo Quantisal é adicionado $100 \mu \mathrm{L}$ de solução saturada de tetraborato de sódio, além de 100 $\mu \mathrm{L}$ de acetonitrila e $50 \mu \mathrm{L}$ de clorofórmio (solventes dispersor e extrator, respectivamente). Posteriormente a esta etapa a mistura é centrifugada e o solvente extrator, agora sedimentado, contém o analito de interesse. A fase orgânica é passada para outro tubo plástico onde é evaporada sob fluxo de nitrogênio e aquecimento $\left(30^{\circ} \mathrm{C}\right)$. $O$ resíduo é ressuspendido com $100 \mu \mathrm{L}$ de metanol e 2 $\mu \mathrm{L}$ são injetados no sistema LC-MS/MS. O método desenvolvido será validado de acordo com o Scientific Working Group for Forensic Toxicology (SWGTOX). ${ }^{2}$

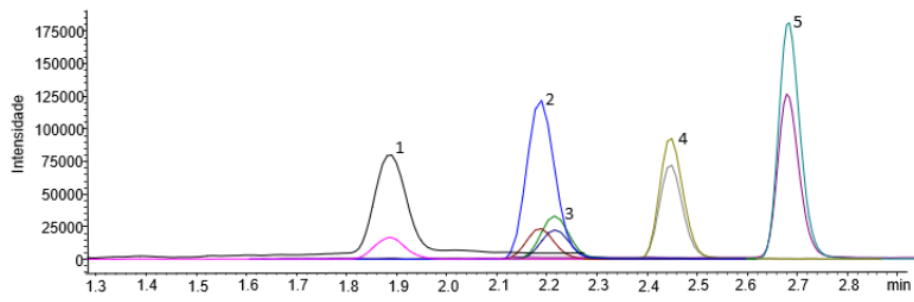

Figura 1. Cromatograma da amostra a $20 \mathrm{ng} / \mathrm{mL}$ (limite de quantificação). 1 Anfetamina; 2 Metanfetamina; 3 MDA; 4 MDMA e 5 MDEA.

\section{Conclusões}

O método está em processo de validação e tem se apresentado preciso e confiável na faixa de linearidade trabalhada $(20-4000 \mathrm{ng} / \mathrm{mL})$. Posteriormente, amostras reais positivas, obtidas de voluntários em festas, serão extraídas e quantificadas sob mesma metodologia.

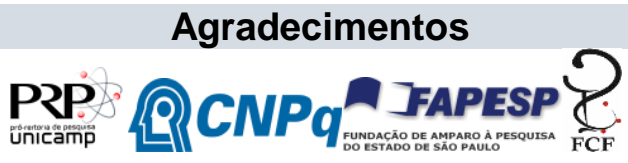

1 UNODC. Word Drug Report. 2019. [https://wdr.unodc.org/wdr2019/] Acesso em Jul, 2019.

${ }^{2}$ SWGTOX Standard practices for method validation in forensic toxicology. J Anal Toxicol. 2013;37(7):452-74 